\title{
Persuasion using Argumentative Strategies, Presuppositions and Directives in Al-Aswany's Political Op-ed Articles
}

\author{
Mona A. S. AbdelFattah ${ }^{1}$ and Abeer M. Refky M. Seddeek ${ }^{2}$ \\ ${ }^{1}$ Arab Academy for Maritime Science and Technology \\ ${ }^{2}$ Affiliation not available
}

November 11, 2021

\begin{abstract}
The study is concerned with Al-Aswany's political opinion articles that have been published since 2011 until 2014 . The study is concerned with argumentative persuasion. It aims at examining how the use of argumentative strategies, presuppositions and directives persuade the reader into accepting the proposed arguments and analyzing the degree of persuasion present in the text. Moreover, the study aims at examining whether there is an attempt to manipulate the reader. The data used, in this study, are drawn from Al-Aswany's opinion articles that have been published in Al-Masry Al-Youm newspaper. The researcher has selected two articles from each year: 2011, 2012, 2013, and 2014. All in all, eight selected articles are gathered for a qualitative analysis. The findings of the study show that his articles are highly persuasive as he, extensively, uses cognitive directives, establishes a common ground through the use of topos of reality and presuppositions, evokes empathy towards the protesters and the revolutions through humanitarianism and justice while raising a feeling of threat/danger from Mubarak's old regime. Furthermore, even though the texts are highly persuasive, to claim that there is a manipulation from Al-Aswany's part, using these linguistic tools and models, can not be strongly suggested.
\end{abstract}

\section{Introduction}

Ever since the onset of the 25/1, drastic changes have occurred in Egypt on different scales: political, economic, societal, etc. These changes have their massive impact on the Egyptian people. One of the major influences of the revolution is that it has unleashed numerous opinions and beliefs. People are no longer restrained as they freely express their different points of view, attitudes, beliefs, and ideologies. The media have facilitated expressing, forming and shaping the public's point of view. Since the start of the first revolution, ideologies have been reproduced, reshaped, or at least influenced. Even writers have had their share of freedom in expressing their views, opinions, and/or attitudes regarding the political events that have occurred since 2011.

One of the prominent most influential writers who have, at times, explicitly and rather vigorously expressed their opinion regarding the political systems in Egypt even before 25/1 is Alaa Al-Aswany. He is well-known for his novels in which he has criticized Mubarak's regime. Al-Aswany is a famous Egyptian novelist and writer who has witnessed a period of corruption followed by two critical revolutions, namely, 25/1 and 30/6 that have had a great influence on the Egyptian society, respectively. Not only is he famous for his writings in Egypt, but also in the Middle East. Furthermore, his work is being translated and published in several languages around the world. He is regarded, by many, inside and outside Egypt as one of the most successful, influential novelists and writers in the region.

\section{Statement of the problem}

During Mubarak's 30 years of presidency, many Egyptians endured a great deal of turmoil, corruption, poverty, persecution, and injustice causing the abruption of 25/1 in 2011. From this point onwards, the 
country has encountered various critical incidents including the second revolution on 30/6, 2013. Egyptians have come across many political figures, systems, events, and incidents during which many opinions were voiced. Al-Aswany is one of the most prominent, influential, and strong voices that have influenced many people during the period from 2011 until he ceased writing in 2014.

The study is mainly concerned with Al-Aswany's opinion articles that were published in Al-Masry Al-Youm newspaper right after the first revolution in 2011 until he refrained from writing in 2014. These articles are highly significant since they portray Al-Aswany's views regarding what has been taking place then. Being printed in the press and, hence, available to the average citizen has highly increased its impact on the reader. In these articles, Al-Aswany expresses his attitude regarding the two revolutions mentioned earlier, the various political systems that occurred before and after the 25/1, political figures like Hosni Mubarak, Egypt's former president from October 1981 to February 2011, Mohamed Morsi, Egypt's former president from June 2012 to July 2013 together with events and incidents that have taken place in Egypt since the onset of $25 / 1$.

The ease of access to his opinion articles, whether in print or online, has contributed to their widespread and, hence, their influence since they would probably form a greater effect as the writer is interacting to convey his opinions, views, beliefs, attitudes, and may be even ideologies to the reader in an interactive context. The reader or receiver, in any written or spoken interaction, is not just a receiver but $\mathrm{s} /$ he has a role in receiving, understanding, negotiating meaning, accepting, or refuting the ideologies presented. This is what makes writing a form of social engagement. Thus, the writers have to do a lot of effort and make use of various tools to communicate the message and persuade their readers into accepting the presented argument.

\section{Research Objectives}

The purpose of the study is to examine how Al-Aswany uses argumentation strategies, presuppositions and directives in persuading the reader, determine the level of persuasion presented in Al-Aswany's articles, and whether there is an attempt to manipulate the reader.

\section{Research Questions}

The study aims at answering the following research questions:

1. How does Al-Aswany use the argumentation strategies, presuppositions and directives in persuading the reader?

2. What is the level of persuasion in Al-Aswany's writing?

3. Is the writer manipulating the reader?

\section{Rational of the Study}

Taking this into consideration, one could argue that Al-Aswany, as a left antagonist writer who is highly influential and as a novelist, can easily express his views in an engaging way to the reader. Moreover, Al-Aswany is a revolutionist, who has in his novels, criticized Mubarak's regime even before the 25/1. He participated also in the revolution and had a lot of influence on people during that time. As a revolutionist and a left antagonist writing opinion articles, Al-Aswany's style of writing is worth studying. His opinion articles are political, and they are concerned with the political regimes and historical events taking place after the first revolution. The articles selected in this study cover critical periods in the history of Egypt. Therefore, studying his articles is very important since they echo one of the most influential voices that has been dominant during that time. Some of these incidents and events include the former military's rule after the revolution, the election for presidency, Morsi's winning of election, $30^{\text {th }}$ of June, etc. these incidents and events are covered in the selected articles and examined through the tools discussed below.

It is obvious, in opinion articles published in newspapers, that the writer is not merely expressing his/her point of view, but, in fact, the writer is most probably persuading his/her addressee into approving and, thus, 
accepting the writer's argument. It is quite interesting to look at the approaches the writer incorporates to persuade the reader. One of these is the use of argumentation. Another element that could be useful, in this investigation, is the use of presuppositions. Furthermore, the use of directives is highly apparent in Al-Aswany's writings. This can be easily identified through examining the use of directives in Hyland's stance and engagement model.

\section{Scope of the Study}

In 2011, Al-Aswany started writing weekly opinion articles after $25 / 1$ and up until 2014 . The articles have been released in the press byAl-Masry Al-Youm newspaper and posted on the newspaper's website. The study examines eight selected articles, two from each year (2011-2014). The selected articles are crucial since they follow important events related to the two revolutions. Not only do they give a brief regarding the incidents, but also the writer's opinion and comments regarding them, and how he communicates them to the reader to persuade him/her into accepting the proposed arguments. The articles were first published in the press and then later on released on the website of the newspaper, which makes these articles easy to access until this moment.

\section{Significance of the Study}

The two revolutions, in 2011 and 2013, have had a huge impact on the whole society and in different fields and disciplines. One of the important fields that need to be investigated in relation to the revolutions is language, whether written or spoken. Language is a tool that reflects ideology and at the same time helps in reshaping it. Many talk shows have been created and many newspaper articles have been released ever since the onset of the first revolution until now. Prominent figures have tried to influence and even twist the paths of the two revolutions by exporting their ideologies to the audience.

The study tackles the attitude of one of the contemporary, most influential, prominent, well-known writers in Egypt and the Middle East. Not only does the writer express his ideologies and point of view, but also he, whether deliberately or inattentively, tries to influence his readers. The writer is able to influence the readers through using a set of linguistic tools to present his argument and engage his readers. Moreover, to the researcher's best knowledge, no linguistic study has examined the articles selected and analyzed in this research.

\section{Literature Review}

By an argument here I mean a set of one or more reasons for doing something, such as-but not limited to-to adopt or maintain an attitude such as a belief but also such as hope, or anger, or expectation; to accept a proposition; or to engage in an activity. (Blair, 2011)

Pinto (2010, p.30) draws a distinctive line between an argument and presenting an argument. Whereas the latter is concerned with "inviting" others through "advocating" an argument to accept its conclusion based on the reasons provided, the former merely states the reasons behind the argument.

By persuasion I mean the concept that is well analyzed by O'Keefe (2002, p. 5) as: ... a successful intentional effort at influencing another's mental state through communication in a circumstance in which the persuadee has some measure of freedom.

Since "mental state" here is meant broadly to include dispositions to act or decisions no less than propositional attitudes such as beliefs or commitments, I do not make a distinction between persuading to (do something) and convincing that (something is the case) (Blair, 2011).

In their definition, Seiter \& Gass state that "persuasion involves one or more persons who are engaged in the activity of creating, reinforcing, modifying or extinguishing beliefs, attitudes, intentions, motivations and/or behaviors within the constraints of a given communication context" (2003, p. 34). Persuasion can also be interpreted as exploiting one's available resource to change people's opinions and consequently their behavior. 
Based on Aristotelian persuasion appeals, Handy (2000) and Goering, Connor, Nagelhout and Steinberg (2011) studied the rhetorical aspects of fundraising discourse: logos (rational), ethos (credibility) and pathos (affective/emotional). The first appeal is concerned with the mind of the reader depending on logic using statistics and facts. The second appeal deals with the writer's credibility by highlighting the organization and the experience of the writer and manifesting a respect and an understanding of the reader's perspective. Finally, the affective aspect deals with the emotional side of the reader. Showing empathy is the key factor as the writer tries to trigger the reader's attitudinal and moral values by appealing to their views. In his study, Goering et al. (2011) provided the participants with an imaginary fundraising letters and a hypothetical US $\$ 100$ which they were required to donate to one of these alleged institutions. The reader has several options either keeping the money, donating the whole amount to an institution or splitting it between two institutions. The results of the study indicated that the power of the emotional appeal should never be underestimated. This is, in fact, consistent with the findings of Kotwal and Power's study since they too have focused on hunger and the human suffering.

In Kotwal and Power's (2015) study, instead of examining these strategies for power or social equality, etc. they used it to examine influence. They studied 29 Indian newspaper articles written in English published from 2011 to 2014 . The results of the study show that the leftist and centrists dwelled heavily on the emotional appeal by focusing on the human suffering and social justice. Their use of the label "food security" is a powerful strong counter-argument making it difficult for the right-wing to dispute.

The difference between persuasion and manipulation basically comes from the fact that persuasion includes the interlocutor's acceptance and consent. Manipulation, on the other hand, means that the exercise of this free will is hindered. if the latter becomes conscious of the goal that the manipulator is pursuing, it is no longer a case of manipulation, even if the manipulated party adopts the attitude or otherwise carries out the behavior sought by the manipulator (Nettel \& Roque, 2011).

Hart (2013), implementing two cognitive theories in psychology together with argumentation strategies, examines immigration-related media discourse. It is argued that persuasion and manipulation share the same goal which is influencing audience's views, judgement, actions and decisions (Hart, 2013; Reisigl and Wodak, 2001). However, two identified factors draw the difference between persuasion and manipulation. While the first is concerned with speech act's exploitation as an argument, the second focuses on the intention of the speaker that is the degree or amount of impact the speaker intends to cast on the audience's judgement, decision and/or actions. In fact, covertness is the key on which manipulation rests, hence, it is very difficult to unfold the speaker's intention. As a result, based on Maillat and Oswald's (2009) work, Hart argues that the major difference between the two is that the latter is depicted mainly from the audience's part. Hart's study concludes that in order for a manipulative act to succeed it works on the means by which the mechanisms controlling our information processing act.

Hart takes the notions of influence and persuasion to a higher level. In his study, he defines heuristics as schemes derived by which certain dilemmas are resolved. However, these schemes are usually "fallible" resulting in errors and biases on which manipulation thrives (Hart, 2013). Consequently, heuristics involving emotions can be considered a successful technique in steering actions and decisions (Cosmides and Tooby as cited by Hart, 2013). Consequently, pathetic fallacy is one of the discursive strategies that through arousing affect manipulation of hearer can occur.

Maillat and Oswald (2009), in their paper, discuss five different criteria by which researchers proposed a definition of manipulation: truth or felicity conditions, speaker interests, covertness, social inequality and intentions. The first criterion states that manipulation occurs when the manipulator uses false statements i.e. lying. In other words, manipulation occurs when Grice's maxim of quality is violated. However, Maillat and Oswald argue that this is not necessarily true. The logic behind their argument lies in the fact that manipulation does not always depend on lying since the manipulator could use sincere propositions with hidden intentions that the addressee is not aware of. In addition, not all false statements are intended for manipulation as shown in their example of Santa. Another dilemma with this method is what Parrett (1978) suggested stating that the use of speech act as a theoretical framework is not compatible since the principle 
of expressibility "I manipulate you + proposition" cannot be applied (as cited by Maillat and Oswald, 2009).

The second aspect, speaker's interest, is addressed. Maillat and Oswald proposed a question of whether a manipulative act could be used to serve the addressee's own interest. In their pursuit, Maillat and Oswald, giving the example of the sick friend with the injection phobia and contrary to Van Dike's belief regarding manipulation, argue that a manipulative act could be used to serve the speaker as well as the hearer's interests. That is to say a manipulative act could be implemented for the hearer's own advantage.

Thirdly, the issue of intention is addressed. They further argued that relying on identifying speaker's intentions is a very difficult approach since manipulation is directly related to covertness making it almost impossible to unfold since the whole idea behind manipulation is that the reader is not able to recognize that $\mathrm{s} /$ he has been manipulated.

The notion of covertness is also tackled. It is argued that in order to succeed manipulative acts have to be covert. The dilemma when focusing on covertness as the criteria by which manipulation is defined is the fact that it is controlled by various elements making it difficult to measure. The overall intention of the act, the discursive strategies, the linguistic strategies as well as the global strategies contribute act as variables when addressing the issue of covertness.

Finally, social inequality is another approach towards defining manipulation. Researchers claim that in order for manipulation to occur, "asymmetry between speaker and addressee(s)" has to be present. It is argued that manipulators abuse this "asymmetrical social conditions" resulting in an imbalanced relation of power and domination between speaker and hearer in which the speaker is placed at the top of the social hierarchy. The counter-argument suggested by Maillat and Oswald state that even though it is common for a person at a higher social position to manipulate someone at a lower place in the ladder of status, knowledge and so on, it is not uncommon for someone placed at a lower level to manipulate a person from a higher position, for example, professor-student, parent-child, etc.

In their defense, they introduce a Relevance theory-based framework as a new definition regarding manipulation focusing on the addressee's mental processing. Their study tackles how a manipulator uses words in a way that force the hearer into a "limited contextual selection" introducing the new definition stated below:

manipulation can be best defined in terms of the constraints it imposes on mental processing ... conditions affecting the reception of a manipulative message; specifically, we will define manipulation as a set of constraints limiting the processes of contextual selection. (Maillat \& Oswald, 2009, p. 361)

Based on Allott and Rubio Fernández's (2002) work, it is argued that certain lexical elements enable the hearer to create "cognitive shortcuts" by which shallow processing occurs, a phenomenon that reduces the effort on the hearer's part in interpreting the communicated message activating the "salient conceptual assumptions" accompanying a certain lexical item (as cited by Maillat \& Oswald, 2009).

Thus, opinion articles are influential tools that can be a threat. As a matter of fact, one can claim that it does not only influence and persuades the reader, but also, using the right strategies and techniques, it could be a tool for manipulation. However, more studies need to be done on opinion discourse implementing different approaches and theoretical frameworks to be able to state such a claim.

First of all, there is the text which aims at examining the text or discourse internal structure for selfcontradictions, problems, inconsistencies, and/ or paradoxes. Another is the "socio-diagnostic critique" which is based on the notion of "demystifying" since it aims at unveiling manipulative or persuasive aspects of a certain text. Finally, it aims at improving communication through future-related prospective critique.

Our analysis and discussion have revealed that although the discourse produced by Johnson Sirleaf to inspire the people in the task of national reconstruction appears to be geared towards achieving group cause, trappings of domination in the discourse cannot be mistaken. Cognitively, the way she skews the thinking of the people in the direction of the positive in spite of the stark realities of the ruins of war that stare the people in the face is interesting. So, in a bid to make the audience form a mental picture of the world painted 
by the rhetor, restrictions are inexorably placed on their freedom of interpretation, thereby suggesting that the world is understood only in terms of what the manipulator feels, thinks and desires. the manipulative rhetoric, as our analysis and discussion have shown, fits in perfectly into the predictable four-part pattern of the 'Pep Talk' of any cause group: the threat, the bonding, the cause and the response. While invoking the threat variable, JohnsonSirleaf intensifies the problems of the Liberian society but then appeals to the bonding factor by assuring the people that no matter the threats, the people's ability to stay united and be loyal and have pride would see them through. She appeals to the cause variable by evoking a sense of duty in the audience and finally the response variable finds expression in her identifying specific actions to be taken by using urgency pleas. (ADEYEMI ADEGOJU, 2013).

Using such devices facilitates the establishment of a writer-reader relationship by drawing and positioning the reader in a dialogue. Therefore, one of the main purposes of using these features in discourse is guiding the reader into certain interpretations. Hyland argues that the writer is aware of the reader's role in accepting or refuting the presented arguments as the reader adopts a critical position at certain points in the reading text. Similar to argumentation, stance and engagement might be considered a tool for persuasion or even manipulation of the intended reader.

One of the discursive strategies that will be used in this study is argumentation. Wodak (2002), in her discussion of argumentation strategies, introduces "topos"

topoi or loci can be described as parts of argumentation which belong to the obligatory, either explicit or inferable premises. They are the content-related warrants or 'conclusion rules' which connect the argument or arguments with the conclusion, the claim. As such, they justify the transition from the argument or arguments to the conclusion. (Kienpointner, 1992 as cited by Wodak, 2001, p.74)

The first argumentative strategy (i.e. topos) is related to advantages and usefulness which simply highlight the positive aspects of an action, leading to its acceptance. Similar to the topos of advantages is the topos of disadvantage and uselessness in which the negative aspects of an action are highlighted resulting in its refusal. As for the topos of definition, assigning certain aspects of a certain label when someone is defined or categorized under it. As for the topos of danger or threat, when the danger or threat of an issue is magnified, it should be prohibited or ceased.

Humanitarianism is concerned with human rights, values, and convictions. Thus, an action that opposes these notions is rejected. Responsibility is another topos that demands a solution to a problem from the people or a group if they were responsible for this problem. Furthermore, justice topos is simply concerned with equality. In other words, when people are rendered equal in certain aspects, they should be treated on the same basis. Moreover, Wodak (2002) introduces topos of burdening or weighing down. The topos is concerned with laying off burden caused by certain problems. Finance topos states that an act to eliminate costs and loss should occur when a certain action is believed to result in a loss or a huge cost of money.

Reality topos claims that an action should be taken based on the reality present. Regarding the number topos, which is similar to van Dijk's "number game", it is stated that if a topos is backed up by number then a certain action needs to be taken. Finance topos claims that any action that leads to a loss or a huge cost of money should by avoided. Topos of law states that a certain action should be prohibited or allowed when it contradicts or conforms to the law. According to Wodak (2002), history topos argues that people should perform or prohibit an action when history has proven the positive or negative consequences of such action. As for culture topos, certain group of people might, in fact, lead to emergence of certain problems or dilemmas. Finally, for abuse topos, an action should be taken against an abuse or a change of the right should take place when this right is abused.

Ashamawi (2012) uses Wodak's (2002) and van Emeren's (1996) argumentative strategies to examine the argumentation used in English and Arabic in newspapers regarding the issue of banning niqab, a veil covering the face, in France, revealing the different argumentation strategies exploited in both Arabic and English newspapers selected. Moreover, how the use of argumentative strategies supports certain group of people might, in fact, Wodak and van Emeren's argumentation strategies, the study incorporates van Dijk's argu- 
mentation moves to examine ideologies. The data are collected from different newspapers. For the English data, the study examined sixteen articles that have been posted online in Daily Telegraph, The New York Times, and The Guardian. Concerning the Arabic data, on the other hand, sixteen articles are gathered from Dar al Hayat, Al Sharq al Awsat, and Al-Youm Al-Sabe'. The data analyzed covered the period from 2009 to 2011.

The findings of the study suggest that topoi play a crucial role in both English and Arabic articles. The two dwell on the topoi of threat and humanitarianism. Even though the topos of law is present in both with the same frequency, the topos is used for different purposes. For the English writers, topos is a means by which they explain the ban law to the reader. On the other hand, for the Arabic articles, writers use this topos to discuss laws regarding human rights. Nevertheless, some topoi are more present in the English articles like burden and number. Some topoi are only present in the English articles but not the Arabic. These are topoi of justice and abuse. The study concludes that topoi is not only used to reflect ideology, but also used, by the arguer, as an essential and influential element in defending their stand point (Ashamawi, 2012).

This is further supported by the findings of Tirkonnen-Condit (1996) as he examined the styles of argumentation present in American, British, and Finnish editorials. The study indicates that, unlike Finnish editorials, American writers always have a clear thesis summary that accompanies sensitive issues to soften possible disagreements. Taking into consideration both Tirkonnen-Condit's and Bolivar's work, one can argue that opinion articles, like editorials, vary, in several aspects, from one country to the other and from one newspaper to the other.

Hyland (2001) examines techniques employed by writers to not only engage but also persuade the reader. Analyzing two hundred and fourty academic articles obtained from eight different fields, Hyland argues that different strategies like use of directives, second person pronouns, reference to shared knowledge and questions are used to involve and position the reader in an attempt to engage and hence persuade the intended addressee. Using such devices facilitates the establishment of a writer-reader relationship by drawing and positioning the reader in a dialogue. Therefore, one of the main purposes of using these features in discourse is guiding the reader into certain interpretations. Hyland argues that the writer is aware of the reader's role in accepting or refuting the presented arguments, consequently, adopting a critical position at certain points in the reading text. Similar to argumentation, stance and engagement might be considered a tool for persuasion or even manipulation of the intended reader.

Based on Hyland's (2005) model of interaction mentioned earlier, Lee (2009) attempts to use this model to examine the way stance and engagement expressions are used in Japanese and American editorials. Lee (2009) argues that even though Hyland's model is devised mainly for academic writing, the model has managed to unveil some contrastive aspects of Japanese and American editorials. Through examining 60 Japanese and American articles (30 for each), the study has found that American editorials incorporates more engagement expressions whereas Japanese editorials use more "questions". Furthermore, American editorials use a wide range of stance and engagement expressions in general. Lee argues that Hyland's model of interaction has not only succeeded in identifying differences in both stance and engagement in academic writing but also in editorials to some extent (Lee, 2009).

Directives ask reader to perform an action or share the writer's perspective on an issue. There are three types of acts in directives: Textual, physical, or cognitive. The first act refers the reader to another part of the text or another text. The physical act requires the reader to perform a certain action in the real world or a certain step in a scientific process. The third is the cognitive act. According to Hyland (2002a, 2005), cognitive acts are the "most threatening" acts since they guide the reader to a certain argument or conclusion and enables the reader to view a certain perspective intended by the reader in order to "get them to understand a point in a certain way". Like directives, questions highly engage the reader and lead them to a certain argument or viewpoint intended by the writer.

Hyland and Jiang (2016) has set out to explore this issue using Hyland's (2005) model of engagement. Drawing on a corpus of 2.2 million words taken from the top five journals in each of four disciplines at three 
time periods, we seek to determine whether reader engagement has changed in academic writing over the past 50 years.

Hyland (2001) examines techniques employed by writers to not only engage but also persuade the reader. Analyzing two hundred and fourty academic articles obtained from eight different fields, Hyland argues that different strategies like use of directives, second person pronouns, reference to shared knowledge and questions are used to involve and position the reader in an attempt to engage and hence persuade the intended addressee. Using such devices facilitates the establishment of a writer-reader relationship by drawing and positioning the reader in a dialogue. Therefore, one of the main purposes of using these features in discourse is guiding the reader into certain interpretations. Hyland argues that the writer is aware of the reader's role in accepting or refuting the presented arguments, consequently, adopting a critical position at certain points in the reading text. Similar to argumentation, stance and engagement might be considered a tool for persuasion or even manipulation of the intended reader.

Another influential tool that could be used to influence reader's mind, thoughts, and ideology is the use of presuppositions. Since presuppositions are not only acknowledged or displayed, i.e. "covert" in nature, which enables the speaker to implicitly transmit different values for various aspects and at the same time does not give a room for criticism, they play a crucial role in influencing public opinions (Degano, 2007).

Degano (2007) concludes that although both types of presuppositions are present, affective presuppositions could be used, as a suggestion for future research, to study ideologies. As for epistemic presuppositions, however, interesting results have been yielded. The results of the study have shown that this type of presuppositions has been used in the press to refer to "weapons of mass destruction" in a way that presented the issue of illegal weapon possession by Iraq as taken for granted forcing this argument to move from an explicit to a more implicit level making it difficult to argue against or criticize the issue. The study claims that corpus linguistics could become a very useful tool if combined with CDA and argumentation theory to form a model for analyzing discourse structure.

The study combines various theoretical and methodological approaches to relate argumentation with critical discourse analysis and corpus linguistics. The study examines the way the British press have used presuppositions and dissociations in preparation for the war on Iraq. Both affective and epistemic types of presuppositions are examined. The latter, presented in the corpus, is composed of two groups. The first group is concerned with presenting allegations as evidence while the other with presenting opinions and judgments as "shared knowledge" (Degano, 2007).

It is possible to find cases of argumentation without persuasion, just as there are cases of persuasion without argumentation. This paper focuses on the overlapping territory, which we propose to call persuasive argumentation. To summarize the preceding, we can define persuasive argumentation as the communicational process by which a persuader seeks to put the persuadee in a favorable disposition that leads the latter to commit to an action presented as desirable. This disposition is obtained by a freely consented acceptance that should lead to a change in behavior. The acceptance results from the examination of the reasons given by the persuader, among which emotions can also play a role (Nettel and Roque, 2011).

An analysis of news headlines and editorials of Globo has shown that the newspaper systematically manipulated its readers, public opinion and politicians in order to promote and legitimate a coup as a constitutionallybased impeachment of Dilma Rousseff. It did so not only by extensive daily reports and editorials about the alleged criminal conduct of Dilma, Lula and the PT, but also through many different discursive strategies, such as presenting accusations as facts, celebrating and legitimating the anti-PT judge Moro, populist coverage of demonstrations, disclaimers, numbers game rhetoric, positive self-presentation, and attacking the accusation that the impeachment was in fact a political coup. By omitting information about the expert opinions of legal scholars or of the international press, for example about the grounds for impeachment, the newspaper is not merely politically biased but engages in serious misinformation. the newspaper becomes the mouthpiece of an ideological conspiracy of the conservative oligarchy to return to political power after 13 years, thereby confirming and continuing its economic power. Because of Globo's near monopoly of TV news, 
millions of Brazilians have little access to alternative, more balanced information. Our corpus consists of the 18 editorials on Dilma, Lula, the PT and impeachment published in the Globo newspaper during the months of March and April 2016, strategically preceding the decision of the Câmara de Deputados to initiate the impeachment procedure against the president. The editorials accompany thousands of news articles in both Globo and the other conservative media, systematically presenting a grotesquely biased form of disinformation about Lula, Dilma and the PT. The editorials have been chosen as the target of this article because they explicitly formulate the opinions of the newspaper. We shall also briefly examine the headlines of the front page news articles about them, because this information is often presupposed in the editorials (a complete analysis of the epistemics of presupposed information in editorials would be an interesting topic of study. the editorials begin to be manipulative when their assertions or presuppositions of the facts are biased or false in ways readers cannot or will not readily check, because in that case we witness partisan and systematic epistemic control of the readers' mental models. Related to this point is that the news reports and editorials hardly pay attention to the legal arguments of many experts against the impeachment. Failing to provide this information is undoubtedly a form of manipulative knowledge management (omission of information). He noticed that the manipulative discourse worked on several aspects: lexical derogation, selective accusations, presuppositions, disclaimers, positive self-presentation, suspicions and accusations as facts, generalizations, numbers game, legitimation of impeachment and delegitimization of the accusation of a coup. (T. A. Dijk, 2017).

The results of the analysis of manipulation in the Rajoy-Rubalcaba and Obama-McCain debates reveal similarities and differences in the use of manipulation. In general terms, the Spanish candidates used more manipulation than the Americans in the same debate time and favored fallacies over any other manipulative process, followed by falsities and insincerities, while the results are more balanced for the American candidates. No doubt, fallacies are preferred because they serve well the purpose of appearing to present a rational argument while, in fact, being deceptive moves designed to influence the result of the discussion to the candidates' own advantage (Cabrejas-Peñuelas, 2015).

The findings revealed that the textual markers used by Persian authors were considerably more frequent than those employed by the American writers. Interestingly, unlike the Persian writers, the American authors enlisted a larger number of interpersonal markers, which made their angle of the subject treatment different (Boshrabadi, Biria \& Zavari, 2014).

Dafouze (2008), explored the role of metadiscourse markers in construction and attainment of persuasion by studying 40 opinion articles taken from the Spanish El País and the British The Times (20 from each newspaper). In this crosslinguistic study, using Hylands's (1998) model, she attempted to identify which metadiscourse categories stand out in this type of text and how they are distributed according to crosscultural or cross-linguistic preference. Moreover, by using a group of informants, she tried to find out how metadiscourse operates as a means of persuasion. The results of this study indicated that in general, Spanish texts used a higher number of textual metadiscourse than English texts while with regard to interpersonal metadiscourse, Spanish texts used a lower number of metadiscourse than English texts. Also, the informants who were asked to participate in the evaluation of metadiscourse as a persuasive tool found the texts with a balanced number of metadiscourse as the most persuasive.

Farazene Moghadam (2017) explored the frequency of occurrence of metadiscourse devices, and the role they play in the construction of persuasion in opinion articles written by English native speakers and Iranian EFL (English as a Foreign Language) writers. A corpus of 60 opinion articles, 30 by American writers and 30 by Iranian EFL authors, was collected and examined using Hyland's (2005) model of metadiscours. The articles were taken from newspapers and news websites in October 2014 and were published in the period from May, 2013 to October, 2014. A quantitative analysis was conducted to determine the frequency of occurrence of metadiscourse devices. The results of the study showed that American writers made use of higher numbers of both interactive and interactional metadiscourse. The opinion articles written by native speakers of English (Americans) are richer in metadiscourse use and enjoy a higher frequency of occurrence in both interactive and interactional, and as a result, in the total number of meta-discourse markers. Hedges which were the 
most frequent devices among interactional markers were used differently and with the value of $\mathrm{p}=0.027$, it was proved that Americans certainly use more hedging markers than Iranians. Self-mentions were also used differently in the corpus with Americans tending to mention themselves a lot more often than Iranians. For self-mentions the obtained $\mathrm{p}$ value was 0.002 . The last subcategory for which the obtained alpha level was lower than 0.05 , was the engagement markers with a $p=0.001$. Engagement markers were used by American writers more frequently than their Iranian colleagues. Opinion articles are written in order to discuss a current issue in the society and to attempt to persuade the reader of the stance taken by the writer toward the issue. To achieve this goal, the writer may invest more on improving the relationship between himself or herself and the reader through interactional devices in the text.

The most frequent strategies which are used in Tehran Times' report are lexicalization and repetition. These two strategies, along with other strategies of vagueness and polarization, are used to give a positive image of the reaction of Russia towards Iran. Similarly, in The Los Angeles Times' report, lexicalization is the most frequent strategy which is used by the writer to give a negative image of the reaction of Russia towards Iran after the speech. The results obtained from the CDA analyses of the news reports showed that ideological manipulations of language can be realized by the deployment of the two general semantic macro-strategies of Van Dijk's (2000) framework: positive self-presentation and negative other- presentation which are manifested by other discursive strategies within this framework (Farahani and Moussa, 2014).

\section{Methodology}

\section{Data and Data Collection Procedure}

The data used, in this study, are drawn from Al-Aswany's opinion articles that have been published in AlMasry Al-Youm newspaper. The data are selected from many articles written by the author and posted on the newspaper's website. The researcher has selected two articles from each year: 2011, 2012, 2013, and 2014. The selected articles are crucial since they follow important events related to the revolutions. Some of these incidents and events include the former military's rule after the revolution, the election for presidency, Morsi's winning of election, $30^{\text {th }}$ of June, etc. These incidents and events are covered in the selected articles below. All in all, eight selected articles are gathered for analysis. The following chronologically ordered articles will be analyzed using the various linguistic tools mentioned earlier:

"mdh ntwq' mn lmjls l'skry...?" maadha natawaqac min almagles alcaskarii

"What should we expect from the Military Council...?" (21/6/2011)

"kyf tqDy 'l lthwr@ fy st khTwtkaifa taqDii calaa althawra fii sit KHaTawaat

"How to eliminate the revolution in six steps?" (2/8/2011)

"qbl 'n tdly bSwtk fy l'd@" qabla ?an tudlii beSawtika fii al?iicadaa

"Before you vote in the re-run" (4/6/2012)

lmdh fz mrsy?" limaadhaa faaza mursii

"Why did Morsi win?" (25/6/2012)

"mlHZt 'l msr lthwr@" mulaHazaat cala masaar al thawra

"Explicit Remarks on the Path of the Revolution" (29/7/2013(

"hl nwfq 'l ldstwr?" hal nuwafiq cala al dustuur

"Should we accept the constitution?" (16/12/2013)

"hl ybHth lmSrywn 'n 'b?" hal yabHath al misryuun can ?ab

"Are the Egyptians looking for a father?" (27/1/2014)

mdh t'rf 'n mrD lkrsy? !' madhaa tacrif can maraD al kursii 
"What do you Know about the Chair (authority) Disease?" (1/4/2014)

\section{Approach}

In its quest, the study adopts a qualitative analysis method as it sets DHA as a conceptual framework that provides the background or context in which the opinion articles emerged and, hence, analyzed. Some of these incidents and events include the former military's rule after the revolution, the election for presidency, Morsi's winning of election, $30^{\text {th }}$ of June, etc. These incidents and events are covered in the selected articles mentioned earlier. Moreover, DHA works with various linguistic tools. DHA has numerous discursive strategies. However, the study focuses on argumentation. The study uses argumentation and presuppositions, not to examine the writer's ideology per se, but to examine the level of persuasion and whether there is an obvious manipulation from Al-Aswany's part.

Not only does the study focus on Al-Aswany's level of persuasion, but also the strategies employed to manipulate his readers. Moreover, the study uses the directives in Hyland's (2005) model of interaction to examine how the writer engages the reader and persuades him since Hyland (2002 \& 2005) discuss how cognitive directives are considered a huge form of threat as it plays with the reader's mind. Finally, the study also uses Van Dijk's (2017) study as a model to study manipulation techniques. Therefore, the study uses eclectic tools to provide reliability and, hence, validity of the analysis and results.

\section{Analysis of the Study}

\section{Argumentation}

The study examines Wodak's argumentative strategies to determine the degree of persuasion. The analysis, presented in Table 1, shows that Al-Aswany's argumentation dwells on several topos: threat, humanitarianism, justice, reality, name-interpretation/definition, law and responsibility. Other topos are number, usefulness, uselessness, history and authority. As a matter of fact, the analysis of the study shows that, in his attempt to persuade the reader, Al-Aswany focuses profoundly on four main topos: threat, humanitarianism, justice and reality.

Topos of Threat. Throughout his argument, Al-Aswany identifies, from his point of view, four antirevolution parties: the former military council, Mubarak's regime and those benefiting from Mubarak's regime such as businessmen whom Al-Aswany refers to as beneficiaries and the Brotherhood. Accordingly, one of the main argumentative strategies Al-Aswany dwells on, heavily, is the topos of threat which, in his articles, can be divided into three main categories: fear of the people, fear of Mubarak's regime and fear of the beneficiaries. The first category, which is the most dominant in the selected articles, addresses the people by raising their awareness of the potential threat and evoking a sense of fear and anxiety among the readers regarding the fate of the revolution and the return of Mubarak's regime. This is highly apparent in sentences $\mathrm{X}$ in Table 1.

However, the second and third categories are not emphasized by Al-Aswany. From his point of view, Mubarak's old regime as well as the beneficiaries' interests are jeopardized by the victory of the revolution. Consequently, they are trying by every means to abort it. In table 1, sentences X illustrate this notion. As a matter of fact, the last two categories are not highlighted to avoid reader's empathy with these two entities. They are only brought up to hint at the presence of hidden agendas as well as the motives, if any, behind the alleged conspiracy that is being weaved against the revolution rather than justifying their actions.

Topos of humanitarianism. The first and most dominant is the notion of "individual suffering" shedding light on, from Al-Aswany's perspective, the different forms of torture that the citizens were subject to in Mubarak's regime and how things have not changed since then. The topos of humanitarianism, according to Kotwal and Power (2015), is used to stir affection and emotions and, hence, arouse sympathy by shedding light on the "individual suffering" which influences the reader and persuades him/her. The second notion portrays $25 / 1$ as the means of obtaining social equality, freedom, dignity and a demand for a decent standard of living, consequently, it has to be protected and saved from any entity that intends to work against it. 
Topos of Justice. The topos of justice is one of the most frequently used argumentative topos by Al-Aswany. The topos of justice is closely related to the topos of humanitarianism. Al-Aswany uses the topos of justice to defend his argument and influence the reader.His reasoning is based on the notion that supporting 25/1 is justice. What the former military council is doing is against $25 / 1$, hence, against justice. The topos of justice is used to cast blame on those who question 25/1 as shown in Table 1 sentence X.

Al-Aswany focuses on the topos of justice as he plays on the reader's conscience. His argument depicts $25 / 1$ as the people's way for achieving justice and equality. However, the four anti-revolution parties act against the revolution and hence against justice. Al-Aswany provides the reader with a negative picture of the different forms of injustice that took place during Mubarak's days setting a valid reason for and an urge to protect the revolution using words liket'dhyb /ta'dhib/torture, qnwn lTwry' / qānūn al-awāri/law of emergency,lqm'y@/al-qam‘'iyah/oppression, and 'hdrt/uhdirat/ wasted . Furthermore, a scarecrow, mentioned in one of the articles, is brought up to the minds of people which is qnwn lTwry' / qānūn al-awäri/ law of emergency imposed and supported by the government. Other words used show, from the Al-Aswany's point of view, the torturing of innocent youth described as slmyyn / silmiyin/ peaceful andshbb mSr/shabāb mir/ Egyptian youth for the reader to sympathize with them as they defend the revolution.

Topos of Reality. Al-Aswany uses a lot of affirmative statements to represent his point of view which make them seem like facts. For example, in throwing accusations, he uses affirmative statements which represent them as mere facts. Al-Aswany states his doubts and thoughts as facts as he throws accusations at the former military council. Moreover, verbs used like $m t n$ ' imtana'a/ refrained from, nfdh /naffadha/ implemented andrfD/rafaa/refused and phrases like mkhTT m'd b'ny@/mukhaaan mu'addan bi'ināya/a carefully prepared planindicate to the reader that the council's actions are undoubtfully deliberate aiming at destroying the revolution. Adjectives likekhy'n traitor /Khäinan/ and 'myl agent /'amilan/ which are serious accusations that need a valid proof and can only be sentenced by a judge, are used to describe Mubarak giving the reader the impression that it is a valid accusation and, hence, a sound argument.

Name-interpretation. The analysis shows that Al-Aswany defines and sets a frame attributing certain characteristics for each party. Al-Aswany mentions five main categories: Mubarak's regime, the beneficiaries, the former military council, the Brotherhood and the people. Al-Aswany, in fact, explicitly states his own definition for each. The first is usually portrayed as the source of corruption, the enemy and, hence, the threat this is shown in sentence X. The second, referred to as flwl/filul/ remnants, is always associated with the old regime as they both maintain the same goal which is seeking their own interests leading to corruption illustrated in sentences X.

The former military council is depicted as a powerful conservative anti-democratic institution as shown in sentence X. As a result, based on his argument, its actions and decisions might, in fact, be counter-productive; thus, it might not be the best party to embrace the revolution.

The Brotherhood is another category defined by Al-Aswany as fascists and terrorists seeking only power. As a result, similar to the beneficiaries, the Brotherhood serve their own interests, thus, they hinder the 25/1 and $30 / 6$. Not only do they hinder the revolution, but also they are one of its major threats as shown in sentences X.

The last party discussed in Al-Aswany's articles is the people. The logic behind his argument is that 25/1 and $30 / 6$ erupted to eradicate people's suffering. For Al-Aswany, the people represent the demonstrators and the ordinary citizens whom he calls lns l'dywn the /al-nās al-'adiyūn/ ordinary people .

Topos of Number. Topos of Number is used to support argumentation. In other words, the reasoning behind the argument is that many people have sacrificed their lives for $25 / 1$; thus, it should be protected and saved from those who are plotting against it as shown in sentences

Topos of Responsibility. The topos of responsibility is another well-utilized argumentative move. As a matter of fact, the wordswjb /wäjib/ duty and wjbn /wājibuna/our duty have occurred 15 times in the selected articles. One of the main aims of this strategy is evoking a sense of reader's responsibility towards 
the different incidents that are taking place in Egypt. The reader is made responsible at one point for supporting President Al-Sissy and at another for supporting the constitution as well as the army in their battle against terrorism.

\section{Presuppositions}

Cognitive Factives. The analysis shows the use of lexical presupposition triggers that indicate a cognitive process or task liket'rf /ta'rif/ you know which is related to knowledge as well as other lexical items such as 'rf /"arifa/ knew and'lm / alima/ knew are usually associated with corruption in general and that of the regime in particular presenting the accusations as mere facts. The lexical item ntdhkr /natadhakkar/ remember (we) present a proposition as factual.

('nt t'rf 'n lmkhlw' kn khy'n w'myl l'kthr mn jhz mkhbrt lkn llDrwr@ 'Hkm).

(2) f wsT hdh lmshhd lDbb 'zyz lqry' wqbl 'n tdl bSwtk f ntkhbt l'd@ 'lyn 'n ntdhkr b'D lHqy'q

Aspectual Change. The analysis shows the use of lexical items likewqf lHl / waqf al-äl/ / halt of the economic situation and twqft /tawaqafat/ ceased presents the country's state after the revolution as idle. The findings of the study highlight that the lexical items $m n^{\prime} / \mathrm{man}^{\prime} /$ and $t m n^{\prime} /$ tamna'/to cease, have occurred eight times. This presupposes that oppression still exists, which and people are still suffering as he saysmn' $/ \operatorname{man}^{\prime} /$ cease.

(3) l'ml yjb 'n ylq bhm f lshr' l'n lmSn' twqft.(4) lbd mn mn'mHkm@ lmdnyyn 'mm mHkm 'skry@ wlfrj 'n 12 'lf mdn mHbwsyn f lsjn lHrb w'd@ mHkmthm 'mm qDyhm lTby' .. (5) yjb 'n ytDmn ldstwr ljdyd $m n$ ' qT' lnsh l'Hzb 'l 'ss dyn ... (6) hw'l lbsT frHw bkhl' mbrk wtwq'w khyr kthyr, lknhm 'l md thlth snwt 'nw mn Iteratives. This type of presuppositions is the most frequently used compared to other types. As shown in Table 4.5, there are two sub-types of iteratives: verbs and lexis. Iterative verbs like $y^{\prime} w d w / y a^{6} \bar{u} d \bar{u} /$ they returned, 'dt /'ádat/ returned, st'd /ista'āda/ retrieved, 'd/‘āda/returned and 'd@/i'āadah/ re-doing which come from the verb ' $\mathrm{w}$ d meaning to return, appear frequently in the data, as shown in examples from 28-57 in Table 4.5, which presupposes that the old regime, corruption, and oppression were present before. Lexical items and phrases associated with this verb areldwl@lqm'y@/al-dawla al-qam'íyah/the repressive state,dwl@mbrk/dawlat mubārak/Mubarak's state, lt'dhyb/ta'dhib/torture, 'Sbt mbrk/'iābāt mubārak/Mubarak's gang, nZm mbrk lfsd/nidhām mubārak al-fäsid/Mubarak's corrupted regime, DbT 'mn ldwl@/ubātamn al-dawlah/state security officersand lTwry' qnwn /qānūn al-awari/ emergency law. Also, the author uses the verbykrr/yukarir/ and nkrr/nukarir/ from the verb k r r which means to repeat, indicating that mistakes have occurred before. Unlike the verb' $\mathrm{w} d$ which occurs with the old regime, the verb $\mathrm{k} \mathrm{r} \mathrm{r}$ is only associated with this group showing that these people work on serving their own hidden agendas playing with the same cards. The second sub-type also appears frequently in the data as shown in Table 4.5. The phrases (x7) mn jdyd / min jadìd/ and (x3) mr@ 'khr /marra ukhrá/, which meanagain, highlight that nothing has changed since the revolution. Also, the word jdyd/@/jadid-ah/ and jdyd /jadidan/ meaning newhas occurred twenty-two times in the data. According to the data presented in Table 4.5, these lexical items are usually associated with the following words: fshy@/fäshìyah/fascism, $n Z m / n i \bar{a} m /$ regim, dstwr/dustūr/ constitution and dkttwry@/diktātūrīyah/dictatorship presupposing that there was an old constitution, an old regime, an old fascism and a previous dictator. The word fshy@ /fashiyah/fascism refers mainly to the Brotherhood; however, Al-Aswany is warning the reader of creating a new fascism in El-Sisi's era. Moreover, the lexical item jdyd/@/jadid-ah/new appears with two figures: 'bdlnSrAbdelNasser and fr'wn The Pharoah hinting at the notion of history repeats itself which is another warning. The use of the lexical item 'khr /ukhrá/ meaning another in jrym@ 'khr/jarima ukhrá/ another crime referring to the Brotherhood also presupposes that there was a previous incident as in example 72 in Table 4.5.

(7) tsrbt 'nb 'n 'wd@ qnwn lTwry'ldh qmt lthwr@llGy'h,wtmt 'd@ DbT'mn ldwl@ lmstb'dyn l mnSbhm lt knw yshGlwnh qbl lthwr@. 
(8) wqd nfdh nZm mbrk mkhTTan dqyqan ljhD lthwr@ w'd@ 'Sbt mbrk1 lslT@...

(9) hdhh lmGlT@ hdfh 'd@ tdwyr nZm mbrk lfsd lstbdd, w'fw'h mn jry'mh,w'ddh lk y'wd l lslT@mn $j d y d$.

(10) flt'ln lHkwm@ bSrH@ 'nh 'zm@ 'l t'dhyb lmSryyn mn jdyd ...

(11) lknn lm 'wfq 'l lTryq@ lt 'dyrt mSr bh b'd 30 ywnyw, fqd'dt ldwl@ lqm'y@wtm lqbD 'l 'shrt l'lwf mn lns, kthyrwn mnhm 'bry lfqt lhm lthm lm'd@ slf w'd lt'dhyb km kn 'ym mbrk wrbm 'sw'...

(12) lkn ll'sf fn lkhwn ykrrwn 'khThm bHdhfyrh, wm n tlwH 'mmhm frS@ ltwl lslT@ Ht t'myhm 'n ' 'tbr akhr mhm tkn 'hmyth.

presuppositions are inferences or propositions, formed by the use of lexical items and linguistic constructions named as presupposition triggers, which make them taken for granted as an undebatable fact in a sentence or utterance. The findings of the study show that there are a lot of lexical items that play the role of presupposition triggers in Al-Aswany's articles. The study focuses on three main types of presuppositions, presented in Table 4.5, that frequently occur in the analysis: cognitive factives, aspectual/change of state predicates and iteratives.

\subsubsection{Cognitive Factives}

\section{Aspectual/Change of State Predicate}

In Table 4.5, most of the lexical items used depict the country's state after the revolution as idle, presupposing otherwise before the revolution, which is considered a negative aspect. The analysis shows the use of lexical items likewqf $l \mathrm{Hl} /$ waqf al-äl/ / halt of the economic situation and twqft/tawaqafat/ ceased in sentences (14) and (16). Other lexical items presuppose that an ongoing process or movement is still taking place mainly acts related to the corruption or oppression of the regime. To illustrate, lexical items such as $l G / i \operatorname{lgh} \bar{a} /$ cancelling, mn'/man'/ prohibiting, Glq/ighlāq / shutting down and frj/ifräg/releasing are found in the analysis. For example, in sentence (13), in Table 4.5, the lexical item $l G / i l g h \bar{a}$ / cancelling hints at the fact that the law is still existing which is considered a sign of oppression. The lexical item lfrj / al-ifräg / releasing presupposes that there are still political prisoners. In Table 4.5, lexical itemslGlq /al-ighlāq/ shutting down and $m n^{\prime} / \mathrm{man}^{\prime} /$ ceasing in sentence (20) presuppose the State Security Service still exists, which is a sign of oppression, and people are still being oppressed as he says $m n^{\prime} / \mathrm{man}^{\prime} /$ cease ,qm' $/$ qam $^{\prime} /$ repress. The findings of the study highlight that the lexical items $m n^{\prime} / \mathrm{man}^{\prime} /$ and $t m n^{\prime} /$ tamna'/to cease, have occurred eight times. In sentences (19), (21) and (24), these lexical items presuppose that there is a great chance the old regime will get back, and civilians are judged by the Military Court which again is a sign of oppression. Such lexical presupposition triggers do not shed light on Mubarak and the former Military council's regime only, but also the corruption of the Brotherhood as well. For example, in sentences (22) and (23), Al-Aswany hints at the presence of corruption related to religious political parties, mainly the Brotherhood. Moreover, the lexical item $y q T^{\prime} / \mathrm{yaqa}^{\prime} /$ end in sentence (26) presupposes that the relationship between Morsi and the Brotherhood is still going on even though he promised otherwise.

\section{Iteratives}

This type of presuppositions is the most frequently used compared to other types. As shown in Table 4.5, there are two sub-types of iteratives: verbs and lexis. Iterative verbs like $y^{\prime} w d w / y a^{6} \bar{u} d \bar{u} /$ they returned, 'dt /'ádat/ returned, st'd /ista'āda/ retrieved, 'd/'āda/returned and 'd@/i'ādah/re-doing which come from the verb ' $\mathrm{w}$ d meaning to return, appear frequently in the data, as shown in examples from 28-57 in Table 4.5 , which presupposes that the old regime, corruption, and oppression were present before. Lexical items and phrases associated with this verb areldwl@lqm'y@/al-dawla al-qam'íyah/the repressive state,dwl@ mbrk /dawlat mubārak/ Mubarak's state, lt'dhyb /ta'dhib/torture, 'Sbt mbrk/'iābāt mubārak/ Mubarak's gang, nZm mbrk lfsd/nidhām mubārak al-fāsid/Mubarak's corrupted regime, DbT 'mn ldwl@/ubāt amn al-dawlah/ state security officersand lTwry' qnwn / qänün al-awari/ emergency law. Also, the author uses 
the verbykrr/yukarir/ and $n k r r$ /nukarir/ from the verb $\mathrm{k} \mathrm{r} \mathrm{r}$ which means to repeat , indicating that mistakes have occurred before. Unlike the verb ' $\mathrm{w} d$ which occurs with the old regime, the verb $\mathrm{k} \mathrm{r} \mathrm{r}$ is only associated with this group showing that these people work on serving their own hidden agendas playing with the same cards. The second sub-type also appears frequently in the data as shown in Table 4.5. The phrases (x7) mn jdyd / min jadìd / and (x3) mr@ 'khr / marra ukhrá / , which meanagain, highlight that nothing has changed since the revolution. Also, the word jdyd/@ /jadīd-ah/ and jdyd /jadīdan/ meaning newhas occurred twenty-two times in the data. According to the data presented in Table 4.5, these lexical items are usually associated with the following words: fshy@/fāshìyah/fascism,nZm /niām/regim, dstwr /dustūr/ constitution and dkttwry@/diktātüriyah / dictatorship presupposing that there was an old constitution, an old regime, an old fascism and a previous dictator. The word fshy@/fāshìyah / fascism refers mainly to the Brotherhood; however, Al-Aswany is warning the reader of creating a new fascism in El-Sisi's era. Moreover, the lexical item jdyd/@/jadìd-ah/new appears with two figures: 'bdlnSrAbdelNasser and fr'wn The Pharoah hinting at the notion of history repeats itself which is another warning. The use of the lexical item'khr /ukhrá/ meaning another in jrym@ @khr/jarima ukhrá / another crime referring to the Brotherhood also presupposes that there was a previous incident as in example 72 in Table 4.5. The lexical item $\mathrm{mrr} /$ miraran/repeatedly and the lexical phrase $\mathrm{mrr} w \mathrm{tkrr} /$ miraran wa tikraran/ over and over have occurred in the data three times also presupposing repetition of events. The latter expression is associated with the Former Military Council and the Brotherhood presupposing that rules have been violated several times before. The former presupposes that the Egyptian people have suffered before several times.

Directives. As shown in Fig. 4.2, directives are the most frequently used feature comprising $38 \%$. As a matter of fact, the cognitive act, based on the findings of the study, is the only type of directives used (see Table A1). Accordingly, as mentioned in Chapter Two, Al-Aswany uses the most dangerous type of acts. In fact, the analysis depicts the use of:

imperative verbs like tkhyl/takhayyal/imagine, ftrD/iftari/assume, Df l /aif ilá/add to as stated in examples (45) and (47).

(45) tkhyl nk t'ml fy wZyf@ mmtz@...

Aspectual Change. The analysis shows the use of lexical items likewqf lHl / waqf al-äl/ / halt of the economic situation and twqft/tawaqafat/ ceased presents the country's state after the revolution as idle. The findings of the study highlight that the lexical items $m n^{\prime} / \mathrm{man}^{\prime} /$ and $t m n^{\prime} /$ tamna $/$ to cease, have occurred eight times. This presupposes that oppression still exists, which and people are still suffering as he saysmn' $/ \operatorname{man}^{\prime} /$ cease.

(3) l'ml yjb 'n ylq bhm f lshr' l'n lmSn' twqft.(4) lbd mn mn' mHkm@ lmdnyyn 'mm mHkm 'skry@ wlfrj 'n 12 'lf mdn mHbwsyn f lsjn lHrb w'd@ mHkmthm 'mm qDyhm lTby' .. (5) yjb 'n ytDmn ldstwr ljdyd mn' qT' lnsh l'Hzb 'l 'ss dyn ... (6) hw'l lbsT frHw bkhl' mbrk wtwq'w khyr kthyr, lknhm 'l md thlth snwt 'nw mn

In Table 4.5, most of the lexical items used depict the country's state after the revolution as idle, presupposing otherwise before the revolution, which is considered a negative aspect. The analysis shows the use of lexical items likewqf $l \mathrm{Hl}$ / waqf al-äl/ / halt of the economic situation and twqft/tawaqafat/ ceased in sentences (14) and (16). Other lexical items presuppose that an ongoing process or movement is still taking place mainly acts related to the corruption or oppression of the regime. To illustrate, lexical items such as $l G / i \operatorname{lgh} \bar{a} /$ cancelling, mn'/man'/ prohibiting, Glq/ighlāq/shutting down and frj /ifrāg/releasing are found in the analysis. For example, in sentence (13), in Table 4.5, the lexical item $l G / i l g h \bar{a}$ / cancelling hints at the fact that the law is still existing which is considered a sign of oppression. The lexical item lfrj / al-ifräg / releasing presupposes that there are still political prisoners. In Table 4.5, lexical itemslGlq /al-ighläq/ shutting down and $m n^{\prime} / \mathrm{man}^{\prime} /$ ceasing in sentence (20) presuppose the State Security Service still exists, which is a sign of oppression, and people are still being oppressed as he says $m n^{\prime} / \mathrm{man}^{\prime} /$ cease,$q m$ ' $/$ qam $^{\prime} /$ repress. The findings of the study highlight that the lexical items $m n^{\prime} / \mathrm{man}^{\prime} /$ and $t m n^{\prime} /$ tamna'/to cease, have occurred 
eight times. In sentences (19), (21) and (24), these lexical items presuppose that there is a great chance the old regime will get back, and civilians are judged by the Military Court which again is a sign of oppression. Such lexical presupposition triggers do not shed light on Mubarak and the former Military council's regime only, but also the corruption of the Brotherhood as well. For example, in sentences (22) and (23), Al-Aswany hints at the presence of corruption related to religious political parties, mainly the Brotherhood. Moreover, the lexical item $y q T$ ' /yaqa' / end in sentence (26) presupposes that the relationship between Morsi and the Brotherhood is still going on even though he promised otherwise.

Iteratives. This type of presuppositions is the most frequently used compared to other types. As shown in Table 4.5, there are two sub-types of iteratives: verbs and lexis. Iterative verbs like $y^{\prime} w d w / y a^{6} \bar{u} d \bar{u} /$ they returned, 'dt /“ădat/ returned, st'd /ista'āda/ retrieved, 'd/‘āda/returned and 'd@/i‘ādah/re-doing which come from the verb ' $\mathrm{w} d$ meaning to return, appear frequently in the data, as shown in examples from 28-57 in Table 4.5, which presupposes that the old regime, corruption, and oppression were present before. Lexical items and phrases associated with this verb areldwl@lqm'y@/al-dawla al-qam'inah/the repressive state,dwl@mbrk/dawlat mubārak/Mubarak's state, lt'dhyb/ta'dhib/torture, 'Sbt mbrk/'iābāt mubārak/ Mubarak's gang, nZm mbrk lfsd /nidhām mubārak al-fäsid/ Mubarak's corrupted regime, DbT 'mn ldwl@/ubātamn al-dawlah/state security officersand lTwry' qnwn / qānūn al-awari/ emergency law. Also, the author uses the verbykrr /yukarir/ andnkrr /nukarir/ from the verb k r r which means to repeat, indicating that mistakes have occurred before. Unlike the verb' $\mathrm{w} d$ which occurs with the old regime, the verb $\mathrm{k} \mathrm{r} \mathrm{r}$ is only associated with this group showing that these people work on serving their own hidden agendas playing with the same cards. The second sub-type also appears frequently in the data as shown in Table 4.5. The phrases (x7) mn jdyd / min jadìd/ and (x3) mr@ 'khr /marra ukhrá/, which meanagain, highlight that nothing has changed since the revolution. Also, the word jdyd/@ /jadid-ah/ and jdyd /jadidan/ meaning newhas occurred twenty-two times in the data. According to the data presented in Table 4.5, these lexical items are usually associated with the following words: fshy@/fäshīyah/fascism, $n Z m / n i \bar{a} m /$ regim, dstwr/dustür/ constitution and dkttwry@/diktātürìyah/dictatorship presupposing that there was an old constitution, an old regime, an old fascism and a previous dictator. The word fshy@ /fäshìah/fascism refers mainly to the Brotherhood; however, Al-Aswany is warning the reader of creating a new fascism in El-Sisi's era. Moreover, the lexical item jdyd/@/jadīd-ah/new appears with two figures: 'bdlnSrAbdelNasser and fr'wn The Pharoah hinting at the notion of history repeats itself which is another warning. The use of the lexical item 'khr/ukhrá/ meaning another in jrym@ 'khr/jarima ukhrá/ another crime referring to the Brotherhood also presupposes that there was a previous incident as in example 72 in Table 4.5.

(7) tsrbt 'nb 'n 'wd@ qnwn lTwry'ldh qmt lthwr@ llGy'h, wtmt 'd@ DbT'mn ldwl@ lmstb'dyn l mnSbhm lt knw yshGlwnh qbl lthwr@.

(8)wqd nfdh nZm mbrk mkhTTan dqyqan ljhD lthwr@w'd@ 'Sbt mbrkl lslT@...

(9) hdhh lmGlT@ hdfh 'd@ tdwyr nZm mbrk lfsd lstbdd, w'fw'h mn jry'mh,w'ddh lk y'wd l lslT@mn jdyd.

(10) flt'ln lHkwm@ bSrH@ 'nh 'zm@ 'l t'dhyb lmSryyn mn jdyd ...

(11) lknn lm 'wfq 'l lTryq@ lt 'dyrt mSr bh b'd 30 ywnyw, fqd'dt ldwl@ lqm'y@ wtm lqbD 'l 'shrt l'lwf mn lns, kthyrwn mnhm 'bry lfqt lhm lthm lm'd@ slf w'd lt'dhyb km kn 'ym mbrk wrbm 'sw'...

(12) lkn ll'sf fn lkhwn ykrrwn 'khThm bHdhfyrh, wm n tlwH 'mmhm frS@ ltwl lslT@ Ht t'myhm 'n ' 'tbr akhr mhm tkn 'hmyth.

presuppositions are inferences or propositions, formed by the use of lexical items and linguistic constructions named as presupposition triggers, which make them taken for granted as an undebatable fact in a sentence or utterance. The findings of the study show that there are a lot of lexical items that play the role of presupposition triggers in Al-Aswany's articles. The study focuses on three main types of presuppositions, presented in Table 4.5, that frequently occur in the analysis: cognitive factives, aspectual/change of state 
predicates and iteratives.

This type of presuppositions is the most frequently used compared to other types. As shown in Table 4.5, there are two sub-types of iteratives: verbs and lexis. Iterative verbs like $y^{\prime} w d w / y a^{6} \bar{u} d \bar{u} /$ they returned, ' $d t$ /'ádat/ returned, st'd /ista'āda/ retrieved, 'd/'āda/returned and 'd@/i‘ādah/re-doing which come from the verb ' w d meaning to return, appear frequently in the data, as shown in examples from 28-57 in Table 4.5 , which presupposes that the old regime, corruption, and oppression were present before. Lexical items and phrases associated with this verb areldwl@lqm'y@/al-dawla al-qam'ìyah/the repressive state, dwl@ mbrk /dawlat mubārak/ Mubarak's state, lt'dhyb /ta'dhıb/torture, 'Sbt mbrk/'iābāt mubārak/ Mubarak's gang, nZm mbrk lfsd/nidhām mubārak al-fäsid/ Mubarak's corrupted regime, DbT 'mn ldwl@/ubāt amn al-dawlah/ state security officersand lTwry' qnwn /qānün al-awari/ emergency law. Also, the author uses the verbykrr/yukarir/ and $n k r r$ /nukarir/ from the verb $\mathrm{k} \mathrm{r} \mathrm{r}$ which means to repeat, indicating that mistakes have occurred before. Unlike the verb' ' $\mathrm{w} d$ which occurs with the old regime, the verb $\mathrm{k} \mathrm{r} \mathrm{r}$ is only associated with this group showing that these people work on serving their own hidden agendas playing with the same cards. The second sub-type also appears frequently in the data as shown in Table 4.5. The phrases (x7) mn jdyd / min jadìd / and (x3) mr@ 'khr /marra ukhrá /, which meanagain, highlight that nothing has changed since the revolution. Also, the word jdyd/@/jadīd-ah/ and jdyd /jadīdan/ meaning newhas occurred twenty-two times in the data. According to the data presented in Table 4.5, these lexical items are usually associated with the following words: fshy@/fāshìyah/fascism, nZm /niām/regim, dstwr /dustūr/ constitution and dkttwry@/diktätüriyah / dictatorship presupposing that there was an old constitution, an old regime, an old fascism and a previous dictator. The word fshy@/fäshīyah / fascism refers mainly to the Brotherhood; however, Al-Aswany is warning the reader of creating a new fascism in El-Sisi's era. Moreover, the lexical item jdyd/@/jadìd-ah/new appears with two figures: 'bdlnSrAbdelNasser and fr'wn The Pharoah hinting at the notion of history repeats itself which is another warning. The use of the lexical item'khr /ukhrá/ meaning another in jrym@ 'khr/jarima ukhrá / another crime referring to the Brotherhood also presupposes that there was a previous incident as in example 72 in Table 4.5. The lexical item $\mathrm{mrr} /$ miraran/repeatedly and the lexical phrase $\mathrm{mrr} w \mathrm{tkrr} /$ miraran wa tikraran/ over and over have occurred in the data three times also presupposing repetition of events. The latter expression is associated with the Former Military Council and the Brotherhood presupposing that rules have been violated several times before. The former presupposes that the Egyptian people have suffered before several times.

Directives. As shown in Fig. 4.2, directives are the most frequently used feature comprising 38\%. As a matter of fact, the cognitive act, based on the findings of the study, is the only type of directives used (see Table A1). Accordingly, as mentioned in Chapter Two, Al-Aswany uses the most dangerous type of acts. In fact, the analysis depicts the use of:

imperative verbs like tkhyl/takhayyal/imagine, ftrD/iftari/assume, Df l /aif ilá/add to as stated in examples (45) and (47).

(45) tkhyl nk t'ml fy wZyf@ mmtz@...

Imagine you have an excellent job ...

(46) ftrD b'd dhlk 'n Hryqan qd shb f ldwr ldh tsknh...

Then, suppose that a fire broke out on the floor where you live...

(47) 'Df $l$ dhlk jhz ldwl@ blkml, ldh snd shfyq bkl qwth...

Add to this, the entire state which has supported Shafiq with all its might...

verbs indicating obligation, which are close to the modal verbs in English, like yjb 'n /yajib an/must/should (occurring 33 times) and ' $l+h+{ }^{\prime} n$ must and phrases like $m n+1+$ 'n/lmSdrsuch as mn $l S^{\prime} b /$ mina al-a'bi/ it is difficult to, mn lshl it is easy to /mina al-sahli/, mn lDrwry ' $n$ it is necessary to /mina al-arürì an/ as shown in examples (48) to (50).

(48) fnn yjb 'n nwfq 'l hdh ldstwr l'n rfDh stkwn lh 'wqb 'sw' bkthyr mn lmHkmt l'skry@ llmdnyyn. 
we must agree on this constitution because rejecting it would have far worse consequences than the military trials of civilians.

(49) f wsT hdh lmshhd lDbb 'zyz lqry' wqbl 'n tdl bSwtk f ntkhbt l'd@ 'lyn 'n ntdhkr b'D lHqy'q...

Amidst this blurry scene, dear reader, and before you cast your vote in the runoff elections, we must remember some facts:

(50) thm twl lkhwn lHkm fzddt l'mwr sw, w'Hs lns b'n lbld qd wq' f 'yd 'frd 'Sb@ mn lS'b st'dth mnhm.

Then the Brotherhood took over, so matters got worse, and people felt that the country has fallen in the hands of gang members which made it difficult to retrieve.

negation as a means of directing the reader using the words of negation such as $l / \mathrm{la} /$ no and lys /layisa/not as shown in example (51).

(51) 30 ywnyw lyst thwr@ mnfSl@ 'm sbqh, l'n lthwrt $l$ tSn' kl 'myn, km 'n mZhrt lywm lwHd (mhm kn Hjmh kbyr)l ymkn 'n tsm thwr@.

June 30 is not a separate revolution from what preceded it because revolutions are not made every two years, and one-day demonstrations (no matter how large they are) cannot be called a revolution.

Cognitive verbs indicating the reader's state of mind, for example,nktshf /naktashif/ we discover , fwjy'n /füjinā/ we were surprised and ntwq'/natawaqa'/ we expect. Sentences (52) to (54) indicate this notion.

(52) whn nktshf 'n l'khT lqnwny@ tHyT blljn@ l'ly mn kl jnb..

And here, we discover that legal violations surround the Supreme Committee from every side.

(53) l hn wl'mr Tby' yHdth f ' bld dymqrT, lknn fwjy'nbtHwyl l'stdh hykl l lnyb@ l'skry@.

Until here, it is a normal situation that can happens in any democratic country, but we were surprised that Mr. Heikal was referred to Military Prosecution.

(54) nHn hn ntwq' mn lmjls l'skr 'n ystm' l lar jmy' wytkhdh mn lkhTwt m yDmn 'dm syTr@ fryq sys b'ynh 'l ldstwr lqdm.

Here, we expect the military council to listen to all opinions and take steps to ensure that no particular political group imposes their control over the next constitution.

lexical items like bd /abadan/ever, fwr /fawran / immediately, wjb/wjbn/wājib/and /wājibunāa duty/our duty , $\mathrm{Tb}^{\prime} / \mathrm{blTb}$ '/biab'/and /ab'an/ of course as illustrated in examples (55) to (58).

(55) n ldhyn y'Twn 'nfshm lHq f Hrq lkny's wzl@ l’DrH@ wtdmyr ltmthyl wthm mn ykhlfwnhm f lr' bl'd llslm wlkfr l ymkn 'bdan 'n ytfhmw ldymqrTy@ 'w yHtrmwh.

Those who give themselves the right to burn churches, remove shrines, destroy statues and accuse those who disagree with their views of being hostile to Islam and atheists can never understand or respect democracy.

(56) n wjb lry'ys mrs 'n ybd' fwr f tHqyq lqSS l'dl mn qtl@ lshhd wr'y@ 'srhm w'lj lmSbyn 'l 'l mstw dkhl mSr 'w khrjh 'l nfq@ ldwl@.

The duty of President Morsi is to immediately start implementing a just retribution against the murderers of the martyrs, taking care of their families and treating the injured in the best way possible inside or outside Egypt at the state's expense.

(57) n wjbn lwTn ylzmn jmy' bd'm jyshn bkl qw@ f Hrbh 'l lrhb...

Our national duty obligates all of us to support our army with full force in its war on terrorism ...

(58) Tb'an stHwl 'n tHl lmshkl@ blHsn , lkn ljr lmz'j ytmd f l'td 'l Hqwqk... 
Of course, you will try to solve the problem in a decent manner, but the annoying neighbor continues to violate your rights...

Based on the analysis of the study, directives are not restricted to single words or phrases, but also includes entire paragraphs. Three out of eight articles start with hypothetical situations requesting a mental act from the reader as illustrated in the following example.

(59) 'zyz lqry', tkhyl 'nk t'ml f wZyf@ mmtz@ brtb kbyr yHlm bh lkthyrwn, lkn lmshkl@ 'n ry'ysk f l'ml shkhS mtGTrs l ytwqf 'n hntk Twl lnhr... 'mmk dhn khtyr mn thnyn : m 'n trfD lhn@ wtntSr lkrmtk, wf hdhh 1Hl@ stkhsr lrtb lkbyr wtfqd 'mlk wtSbH f lshr', wlkhtyr lthn hw 'n tHwl lt'ysh m' lhn@ wttHml ldhll lknk stn'm lrtb wlHy@ lrGd@... lkhtyr l'wlldh yrfD lhn@ wytmsk blkrm@, bGD lnZr 'n lnty'j, hw m yj'lk thwry... lthwr@ h 'n tfDl lm'n 'l lmSlH@, 'n tqdm lmbd' 'l lmnf'@.. lthwr@ h 'n trfD kl m yqyd nsnytk... hdh blDbT m Hdth f thwr@ mSr

Dear reader, imagine that you have an excellent job with a large salary that many dream of, but the problem is that your boss is an arrogant person who does not stop insulting you throughout the day ... You have one of two choices: either you refuse the insult and triumph for your dignity. In this case, you will lose the big salary, your job and live on the street; meanwhile, the second choice is to try to cope with the insult and endure the humiliation while enjoying the salary and the good life... The first choice that refuses the insult and clings to dignity, regardless of the results, is what makes you a revolutionary... The revolution means that you prefer the meaning over the interest; in other words, choose the principle over the benefits. The revolution is to reject all What restricts your humanity... This is exactly what happened in the Egyptian revolution

As can be seen in example (59), Al-Aswany starts the article entitledmdh ntwq' mn lmjls l'skry? /mādhā natawaqa' min al-majlis al-'askarī/ What do we expect from the military council? by directly addressing the reader asking him to perform a cognitive task using the imperative verb tkhyl/takhayyal/imagine. In this hypothetical situation as well as the others, not only does he impose a certain imaginary situation on the reader, but also, he offers him/her solutions indicated by using mmk khtyr mn thnyn /amāmaka ikhtiyār min ithnayn/ you are faced with one of the following options and $m$ ' $n$ /imma an/ either leading him/her to a certain chosen answer imposed again by Al-Aswany as he says lkhtyr l'wl. . hw m yj'lk thwry /al-ikhtiyār al-awwal... huwa mā yag'aluka thawriyan/ the first... is what makes you a revolutionist. In fact, according to the findings of the study, all the hypothetical situations follow the same pattern that is first requesting the reader to perform a mental task then provide certain limited logical choices followed by Al-Aswany's best selection from his point of view.

\section{Conclusion}

\section{References}

Degano, C. (2007). Presupposition and dissociation in discourse: A corpus study. Argumentation, 21(4), 361-378. doi: 10.1007/s10503-007-9058-7

Devitt, A.J. (2004). Writing Genres. Carbondale: Southern Illinois University Press.

Fairclough, N. (1996). Language and power. New York;London;: Longman.

Florêncio, J. A., \& Scotta-Cabral, S. R. (2013). "How Obama can use pressure to bring peace ": a favorable stance and positive attitudinal assessment. Linguagem e Ensino, 16(2), 481-503.

Goering, E., Connor, U. M., Nagelhout, E., \& Steinberg, R chain that is one argument is the starting point of another. (2011). Persuasion in fundraising letters: An interdisciplinary study. Nonprofit and voluntary sector quarterly, 40(2), 228-246. doi: 10.1177/0899764009339216

Hyland, K. (2002). Directives: Argument and engagement in academic writing. Applied linguistics, 23(2), 215-239. doi: 10.1093/applin/23.2.215 
Mansouri, S., Biria, R., Najafabadi, M. M., \& Boroujeni, S. S. (2017). Nomination and Argumentation Strategies in Oratory Discourse: The Case of an English Sermon. SAGE Open, 7(2), 1-8. doi: $10.1177 / 2158244017702425$

Žagar, I. (2010). Topoi in critical discourse analysis. Lodz Papers in Pragmatics, 6(1), 3-27. doi: $10.2478 /$ v10016-010-0002 